\title{
Optimization of nitrogen and phosphorus removal from meat processing wastewaters using microalgal biofilms
}

\author{
Soroosh Danaee, Hamideh Ofoghi*, Seyed Mohammad Heydarian, Abbas Farazmand \\ Biotechnology Department, Iranian Research Organization for Science and Technology, Tehran, Iran
}

\begin{abstract}
Background: The conventional activated sludge processes are not able to completely treat the nitrogen and phosphorus compounds of meat processing wastewaters. Microalgal biofilm, which has the advantages of easiness and inexpensiveness, can be applied as a post-treatment method.

Methods: The optimal levels of micronutrients and N/P ratio were aimed in the cultivation of Scenedesmus quadricauda as a biofilm formed on the two types of commercially available bed packing. For this purpose, the Factorial design was run to maximize the removal of ammonium, nitrate and phosphate concentration in the synthetic meat processing wastewater.

Results: Experimental data showed better results for the removal of biofilm formed on the sponge filter. In addition, a maximum removal efficiency of $55.6 \%, 47 \%$ and $48 . \%$ was respectively achieved for ammonium, nitrate and phosphate at optimal N/P ratio of 10.5 and volumetric percentage of $50 \%$ of micronutrients.

Conclusion: The results demonstrated that microalgal biofilm of Scenedesmus is able to remove the nutritional components of meat processing wastewaters. The process is needed to be optimized for the effective treatment.

Keywords: Meat, Biofilms, Microalgae, Wastewater, Scenedesmus

Citation: Danaee S, Ofoghi H, Heydarian SM, Farazmand A. Optimization of nitrogen and phosphorus removal from meat processing wastewaters using microalgal biofilms. Environmental Health Engineering and Management Journal 2018; 5(2): 79-84. doi: 10.15171/EHEM.2018.12.
\end{abstract}

\author{
Article History: \\ Received: 28 January 2018 \\ Accepted: 17 April 2018 \\ ePublished: 10 May 2018
}

\section{Introduction}

Common wastewater treatment systems, known as conventional activated sludge processes, are not sufficiently effective in complete removal of some nutrients such as nitrogen and phosphorus compounds (14). Additional cost of the post-treatments caused release of some enriched effluents without proper treatment which in turn led to the environmental problems $(1,2,4)$. Biological treatment processes have been introduced as an alternative for their low cost and high efficiency. Nitrogen compounds can be converted through nitrification/ denitrification processes which have some disadvantages: additional demand of oxygen and carbon sources, $\mathrm{N}$ loss in gaseous form, toxic side products $\left(\mathrm{NO} / \mathrm{N}_{2} \mathrm{O}\right)$, etc (5). Phosphorus compounds can be accumulated by polyphosphate accumulating organisms (PAOs) which have the disadvantages of disposal of sludge residues and unstable removal efficiencies (5).

Cultivation of microalgae is rising up in the removal process of nutrient compounds with advantages of nutrient recovery, valuable biomass production, inexpensive oxygenation and heavy metals adsorption (5). However, most of the single cell microalgae are accompanied by the problems of separation in downstream processes in which $20 \%-30 \%$ of the total cost of the process accounts for the biomass separation. Algal immobilization techniques can be used as alternatives to reduce the process costs and separation problems (1-3).

Numerous studies have been conducted on the removal of nutrient compounds from wastewater using immobilized microalgae; in addition, the effects of various factors have been investigated in recent years (2,6-9). Optimization of the nitrogen to phosphorus $(\mathrm{N} / \mathrm{P})$ ratio in the wastewater seems to be of great importance to increase the efficiency of compounds removal. Guzzon et al used a photosynthetic biofilm, taken from a sedimentation tank, to remove phosphorus from the wastewater of Rome airport, and modified N/P ratio up to 15 by adding nitrate and phosphate to the wastewater (10). Boelee et al also assessed the removal capability of nutrient compounds from synthetic urban wastewater in post-treatment process using microalgal biofilms. Although micronutrients of WC medium were used in this study, but the effects of using these compounds in the microalgal treatment were 
not investigated (2). The effect of nutritional components on the growth of microalgae was investigated previously $(11,12)$, but to our knowledge, no research has been conducted to investigate nutritional components as the variables in the wastewater treatment.

The present study was conducted for the first time with the aim of determining the optimal levels of two factors of the micronutrients and N/P ratio in the microalgal post-treatment of synthetic meat processing wastewater. For this purpose, two types of bed packing, which are commercially available, were used in this study. In addition, the effect of the beds was also compared in this study.

\section{Methods}

Microalgae, Scenedesmus quadricauda, was prepared (13) and cultured in Bold's Basal Medium (BBM) at temperature of $25^{\circ} \mathrm{C}$, light of 3000 lux for approximately 10 days to prepare inoculum. It was then inoculated into two 6-L glass columns (with an internal radius of $9 \mathrm{~cm}$ and height of $100 \mathrm{~cm}$, at $25^{\circ} \mathrm{C}, 3000$ lux and $16: 8$ photoperiod) to reach an approximate density of $3 \times 10^{7}(3,14)$. Then, two types of bed packing (Yellow Sponge Filter and High Friction Grooved Rasching Ring Packing [HFGRRP]) were added to the middle section of each column so that the microalgal biofilm was formed on their specific surface area under a laminar flow (Figure 1) $(2,3,14)$. Bed packings characteristics are presented in Table 1. The synthetic wastewater that was prepared equivalent to the major compounds of an industrial meat processing unit and used in the experiments, containing (analytical grade): magnesium sulfate $(73.93 \mathrm{mg} / \mathrm{L})$, sodium nitrate $(21.934 \mathrm{mg} / \mathrm{L})$, sodium carbonate $(73.42 \mathrm{mg} / \mathrm{L})$, ammonium chloride $(68.3 \mathrm{mg} / \mathrm{L})$, potassium dihydrogen phosphate $(0.34 \mathrm{mg} / \mathrm{L})$, dipotassium hydrogen phosphate $(0.226 \mathrm{mg} / \mathrm{L})$. Organic carbon was not used in the preparation of the synthetic wastewater in order to limit the bacterial growth (2).

Experiments were designed by the factorial design method with three factors: Micro-elements of BBM culture medium (13), N/P ratio, and changes in the type of bed packing (both with the same volume) with two central

Table 1. Bed packings characteristics

\begin{tabular}{lll}
\hline & Sponge Filter & HFGRRP \\
\hline Material & Polyurethane & Polyethylene \\
Specific surface area $\left(\mathrm{m}^{2} / \mathrm{m}^{3}\right)$ & 800 & 899 \\
\hline
\end{tabular}

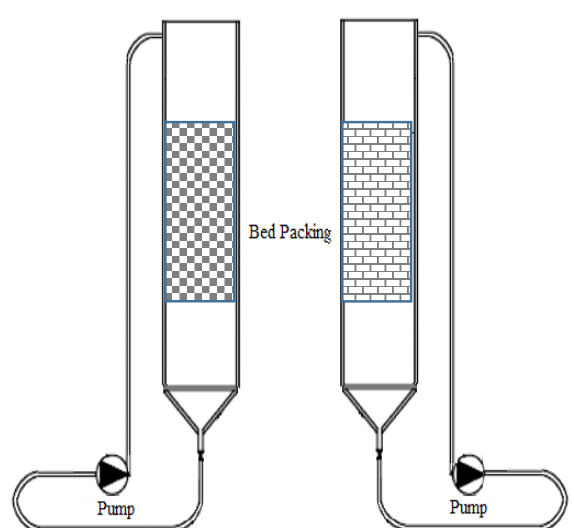

Figure 1. Diagram of photobioreactors used for algal attachment on the bed packings.

points. The levels of these factors are shown in Table 2. The bed packings covered with microalgal biofilm were transferred to the flasks (3). Then, the performance of the biofilm of Scenedesmus was assessed in the synthetic meat processing wastewater at different levels of the factors to determine the maximum removal efficiency by Minitab software (version 14). During the removal process, the concentration of nutrient compounds (ammonium, nitrate and phosphate) was measured by standard water and wastewater analysis $\left(4500-\mathrm{NH}_{3} \mathrm{C}, 4500-\mathrm{NO}_{3}{ }^{-} \mathrm{B}, 4500\right.$ $\mathrm{P} \mathrm{D}$, respectively) (15). Furthermore, parameters of $\mathrm{pH}$, total dissolved solids (TDS), and electrical conductivity (EC) were measured in several days. Then, the mean of three replicates was used in the Factorial design.

\section{Results}

Variations of the three variables of ammonium, nitrate and phosphate concentrations during the growth of microalgal biofilm of $S$. quadricauda formed on the PB are presented in Figure 2. These results were obtained based on the combination of experimental design of the two factors of the N/P ratio and the volumetric percentage of nutrient compounds in the synthetic wastewater. As shown in Figure 2, ammonium was gradually declined during the removal process, however, nitrate was slightly decreased in the first few days. Phosphate removal also had a declining trend during the experiments (Figure 2). The removal efficiency of nitrate and ammonium in $\mathrm{PB}$ varied between $20 \%$ and $55 \%$, and its highest rate was measured at N/P ratio of 10.5 and $\mathrm{BBM}$ micronutrient

Table 2. Levels of factors in the Factorial design

\begin{tabular}{llll}
\hline Factor & High Level & Center Point & \\
\hline BBM Nutritional components & $100 \%$ (volumetric) of micronutrient solution & $50 \%$ (volumetric) of micronutrient solution & - \\
N/P ratio & 7 & 10.5 & 14 \\
Bed & Sponge Filter (SF) & & Packed Bed (PB) \\
Total run & 20 & & \\
\hline
\end{tabular}




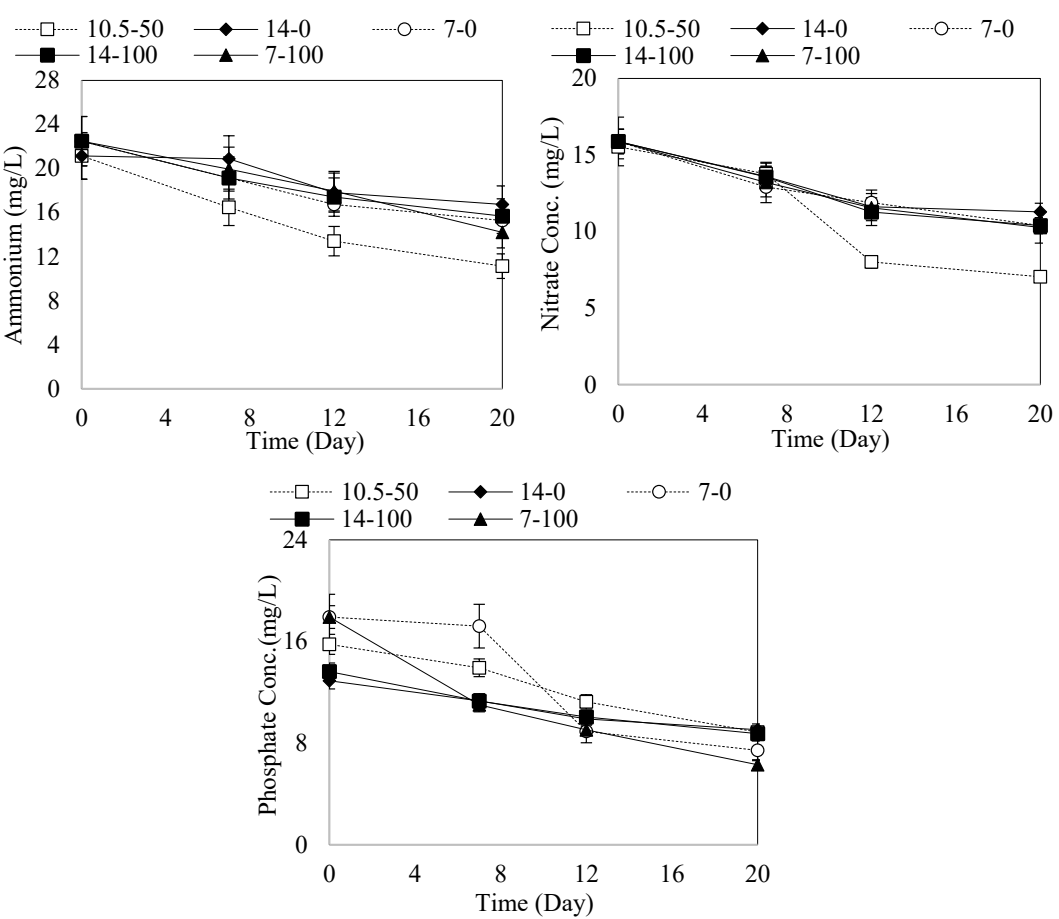

Figure 2. Ammonium, nitrate and phosphate concentrations of wastewater during the growth of Scenedesmus quadricauda on PB in different $\mathrm{N} / \mathrm{P}$ ratios and volumes of the micronutrients.

solution in the volumetric percentage of $50 \%$, which was obtained $55 \%$ and $47 \%$, respectively. The maximum removal efficiency of phosphate was obtained at a lower $\mathrm{N} / \mathrm{P}$ ratio, so that in the presence of $\mathrm{BBM}$ micronutrient solution and the N/P ratio of 7 , about $62 \%$ of the initial phosphate was decreased after 20 days.

The effects of the variables on microalgal biofilm of $S$. quadricauda formed on the SF bed were investigated in a synthetic wastewater; the results of wastewater removal are illustrated in Figure 3. In comparison with the previous graph, it can be seen that the trends are similar, so that the highest removal efficiency of nitrate and ammonium obtained in the same condition, was $55.6 \%$ and $47 \%$, respectively. At a lower N/P ratio, the phosphate removal process had a better condition, so that the maximum removal efficiency obtained in the presence of micronutrient solution and at N/P ratio of 7 , was $66.6 \%$, while at the center point of experimental design, phosphate removal efficiency was $48.4 \%$ (Figure 3 ).

Figure 4 shows the optimal points (presented in red color) and desirability (presented as "d") for the simultaneous removal of all three compounds. The values obtained for the removal efficiencies (presented in blue color as " $y$ "), were adjusted in the software. The software reported the $\mathrm{N} / \mathrm{P}$ ratio of $10.5, \mathrm{BBM}$ micronutrient solution in the volumetric percentage of $50 \%$ and $\mathrm{SF}$ as the optimum condition (Figure 4).

Figure 5 shows the trends of EC and TDS in the treated wastewater by Scenedesmus grown on $\mathrm{PB}$ and SF. The experimental data showed a maximum reduction of $64 \%$ by $\mathrm{PB}$ and $77 \%$ by SF in TDS as a result of the treatment process (Figure 5).

\section{Discussion}

The biological removal trends of ammonium and nitrate were the same in both beds, so that the concentration of nitrate in the first 8 days had an approximate slight reduction, however, the microalgal removal rate then increased by more than $80 \%$, while the removal rate of ammonium decreased during the first days. This can be due to the preferred form of nitrogen source in $S$. quadricauda (16). In a study carried out on this strain, unlike ammonium, variations of nitrate concentration were low in the first 7 days (17). In another study, no significant changes were observed in nitrate concentration during the first 5 days (18). In the present study, nitrate concentration had also little changes after 8 days.

In addition, the micronutrient solution had a positive effect on the biological treatment. This can be due to the higher production rate of chlorophyll in the presence of BBM micronutrient solution $(12,19)$. In a study conducted on $S$. quadricauda, the maximum removal of nitrogen source was observed in the presence of a BBM micronutrient solution (20).

Variations of the N/P ratio were the same in both sources of nitrogen, which was also observed in other studies (21), because despite the priority of the use of ammonium source, both sources were finally eliminated with the approximate same value. In addition, in both beds, the optimum removal rate for ammonium and nitrate was at 


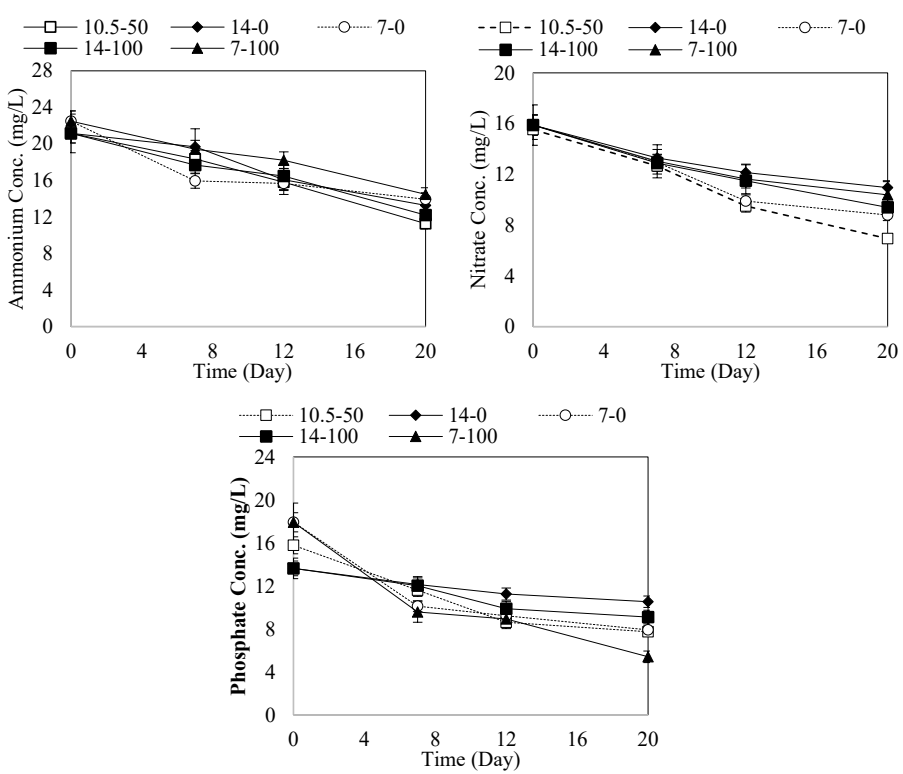

Figure 3. Ammonium, nitrate and phosphate concentrations of wastewater during the growth of Scenedesmus quadricauda on SF in different N/P ratios and volumes of the micronutrients.

the $\mathrm{N} / \mathrm{P}$ ratio of 10.5 and in the presence of micronutrient solution. One of the reasons for the importance of this ratio and its effect on the growth and removal of nitrogen and phosphorus sources is the effect of this parameter on the production of chlorophyll. This was reported in a study that the maximum chlorophyll was produced at N/P ratios between 10 and 12 (22). In another report, the maximum removal of TN and biomass production was measured at $\mathrm{N} / \mathrm{P}$ ratio of 10 , in addition, $\mathrm{TN}$ removal was significantly reduced at N/P ratio of 15 (23). In a report by Zhang et al, $S$ quadricauda which was immobilized on calcium alginate, was exploited to treat urban wastewater, with

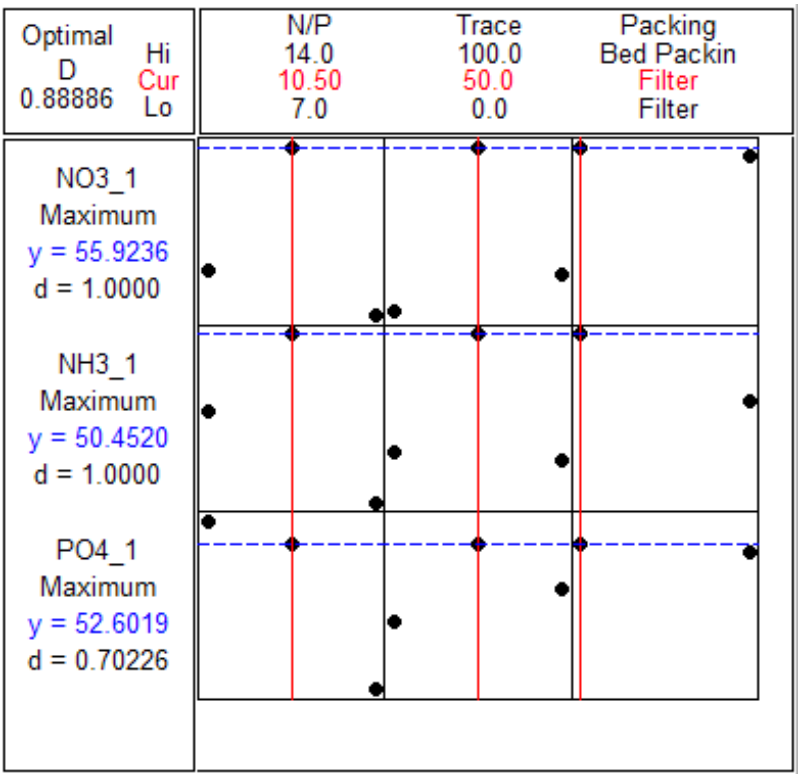

Figure 4. Results of optimum conditions based on the maximum removal efficiency of ammonium, nitrate and phosphate. the optimal N/P ratio of 10 for ammonium removal (4). In another study on urban wastewater treatment using $S$. quadricauda, the rate of biomass production and biological removal of TN increased and then decreased by increasing the $\mathrm{N} / \mathrm{P}$ ratio to 10 , so that the rate of biomass production at the ratio of 10 was $2.9 \mathrm{~g} / \mathrm{L} / \mathrm{d}$, which decreased to 1.9 $\mathrm{g} / \mathrm{L} / \mathrm{d}$ by doubling the $\mathrm{N} / \mathrm{P}$ ratio. Like phosphate removal rate in the present study, the maximum removal of TP was obtained at N/P ratio of less than 10 , and with increasing this ratio, the phosphate removal rate was decreased (24). In another study conducted on the biofilms, the removal percentage for phosphate reached from $45 \%$ to $100 \%$ with increasing its concentration from 0.9 to $1.55 \mathrm{mg} / \mathrm{L}$ (2).

In the present study, the maximum removal levels of ammonium and nitrate were obtained at N/P ratio of 10 with an initial concentration of $21.2 \mathrm{mg} / \mathrm{L}$ and $40 \mathrm{mg} / \mathrm{L}$, respectively, in both beds. On the other hand, the removal rate increased by increasing the amount of phosphate in the growth medium of both beds, so that the maximum removal efficiency of phosphate was measured at $\mathrm{N} / \mathrm{P}$ ratio of 7. This is due to the increased phosphate absorption with an increase in its concentration (2).

After 20 days of culture in the two beds under optimal conditions, the removal efficiency of nitrate in the $\mathrm{PB}$ and SF beds was 55 and 56\%, respectively. In addition, the ammonium removal efficiency in the two beds was 47.3 and $47 \%$, respectively. This indicates that changing the type of beds had less effect on the results compared to the other factors. Nevertheless, the removal efficiency of phosphate in the SF bed was better under optimal conditions, as the removal efficiency was 66.6 and $61.9 \%$ for the SF and $\mathrm{PB}$, respectively. This is due to the high surface area of the SF compared to the PB. Hence, the nutrient uptake increases by increasing the specific 

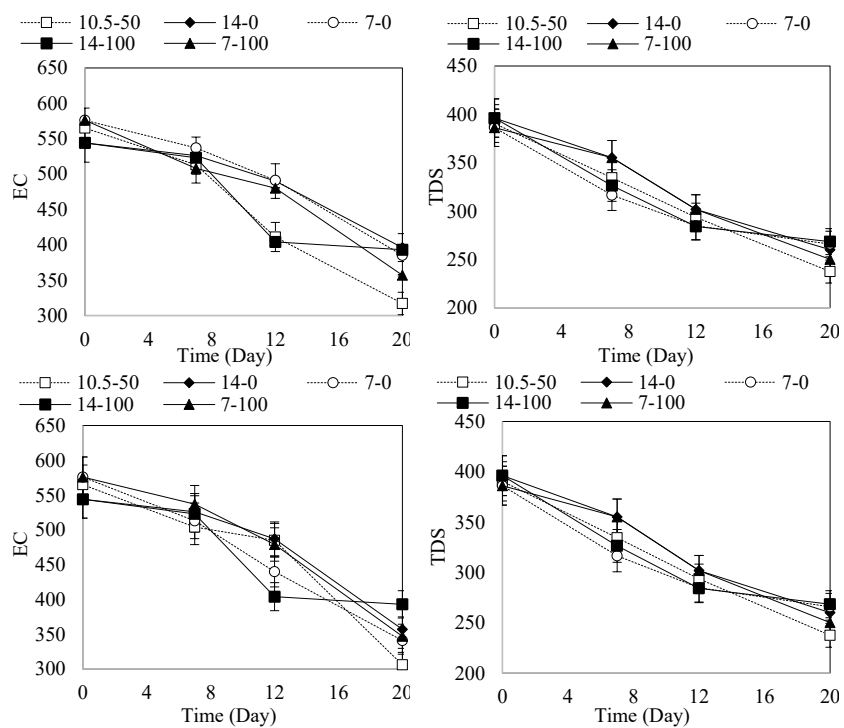

Figure 5. EC and TDS of treated wastewater by Scenedesmus grown on the PB (above) and SF (below).

surface area (9), while low diffusion rate of the nutrient compounds into the biofilm and incomplete ammonium removal can be effective in the reduction of assimilations rates through the biofilm $(2,14)$.

In the present study, the maximum rate of removal for phosphate, ammonium, and nitrate in the $\mathrm{PB}$ was $2 \mathrm{mg} /$ $\mathrm{L} / \mathrm{d}, 0.7 \mathrm{mg} / \mathrm{L} / \mathrm{d}$, and $1.4 \mathrm{mg} / \mathrm{L} / \mathrm{day}$, respectively. This rate for the micronutrients in the SF bed was $2.4 \mathrm{mg} / \mathrm{L} / \mathrm{d}, 0.6$ $\mathrm{mg} / \mathrm{L} / \mathrm{d}$, and $1.4 \mathrm{mg} / \mathrm{L} / \mathrm{d}$, respectively. In a report published in 2007, two strains of Chlorella vulgaris and Scenedesmus rubescens were immobilized on a bed in which the removal rate of phosphate, ammonium, and nitrate was $1 \mathrm{mg} / \mathrm{L}$, $2.2 \mathrm{mg} / \mathrm{L}$, and $0.25 \mathrm{mg} / \mathrm{L}$ at the initial concentrations of $3 \mathrm{mg} / \mathrm{L}, 21 \mathrm{mg} / \mathrm{L}$, and $2.5 \mathrm{mg} / \mathrm{L}$, respectively (21). These results are similar to the present study. Furthermore, Boelee et al, in their study on phosphate, ammonium, and nitrate assimilation using a biofilm microalgae consortium, reported the removal rates of $2 \mathrm{mg} / \mathrm{L} / \mathrm{d}, 2.5$ $\mathrm{mg} / \mathrm{L} / \mathrm{d}$, and $0.6 \mathrm{mg} / \mathrm{L} / \mathrm{d}$, respectively (2). Similarly, Wei et al reported a removal rate of $4 \mathrm{mg} / \mathrm{L} / \mathrm{d}$ for ammonium and $80 \%$ removal of ammonium (with initial concentration of $18 \mathrm{mg} / \mathrm{L} / \mathrm{d}$ ) using a biofilm containing five different types of microalgae. They also reported the removal rate of $2 \mathrm{mg} /$ $\mathrm{L} / \mathrm{d}$ for phosphate at concentration of $10 \mathrm{mg} / \mathrm{L} / \mathrm{d}(9)$. The results indicate that the rate and final removal efficiency of compounds in the present study are consistent with those of previous studies.

It can be observed that the use of minerals by microalgae leads to a decrease in EC and TDS according to Figure 5. This could be an indication of ammonium, nitrate and phosphate removal by $S$. quadricauda microalgae.

\section{Conclusion}

The present study showed the ability of microalgal biofilms in the post-treatment of synthetic meat processing wastewater. A maximum removal efficiency of $47 \%$ for ammonium, $55 \%$ for nitrate and $66 \%$ for phosphate was achieved during the experiments. However, as the results reveal that inadequate phosphorus and nutritional components can significantly affect the removal efficiencies, therefore, an optimization is needed for increasing the effectiveness of microalgae-based wastewater treatment.

\section{Acknowledgments}

The authors would like to thank the staff of Biotechnology Department of Iranian Research Organization for Science and Technology with a special thanks to Mr. Sheikhi Nejhad.

\section{Ethical issues}

The authors have thoroughly observed ethical issues, including plagiarism, misconduct, data fabrication, and redundancy.

\section{Competing interests}

The authors declared no competing interests.

\section{Authors' Contributions}

All authors contributed equally to the study, and all authors participated in data acquisition, analysis, and interpretation. All authors critically reviewed, refined, and approved the manuscript.

\section{References}

1. Aslan S, Kapdan IK. Batch kinetics of nitrogen and phosphorus removal from synthetic wastewater by algae. Ecol Eng 2006; 28(1): 64-70. doi: 10.1016/j. ecoleng.2006.04.003.

2. Boelee N, Temmink H, Janssen M, Buisman C, Wijffels R. Nitrogen and phosphorus removal from municipal wastewater effluent using microalgal biofilms. Water Res 
2011; 45(18): 5925-33. doi: 10.1016/j.watres.2011.08.044.

3. Irving TE, Allen DG. Species and material considerations in the formation and development of microalgal biofilms. Appl Microbiol Biotechnol 2011; 92(2): 283-94. doi: 10.1007/s00253-011-3341-0.

4. Zhang E, Wang B, Wang Q, Zhang S, Zhao B. Ammonianitrogen and orthophosphate removal by immobilized Scenedesmus sp. isolated from municipal wastewater for potential use in tertiary treatment. Bioresour Technol 2008; 99(9): 3787-93. doi: 10.1016/j.biortech.2007.07.011.

5. Su Y. Settleable algal-bacterial culture for municipal wastewater treatment [dissertation]. Lüneburg: Leuphana Universität Lüneburg; 2012.

6. Babu M. Effect of Effect of Algal Biofilm and Operational Conditions on Nitrogen Removal in Waste Stabilization Ponds: UNESCO-IHE PhD Thesis. CRC Press; 2011.

7. Hoffmann JP. Wastewater treatment with suspended and nonsuspended algae. J Phycol 1998; 34(5): 757-63. doi: 10.1046/j.1529-8817.1998.340757.x.

8. Sabater S, Guasch H, Romaní A, Muñoz I. The effect of biological factors on the efficiency of river biofilms in improving water quality. Hydrobiologia 2002; 469(1-3): 149-56. doi: 10.1023/A:1015549404082.

9. Wei Q, Hu Z, Li G, Xiao B, Sun H, Tao M. Removing nitrogen and phosphorus from simulated wastewater using algal biofilm technique. Front Environ Sci Eng China 2008; 2(4): 446-51. doi: 10.1007/s11783-008-0064-2.

10. Guzzon A, Bohn A, Diociaiuti M, Albertano P. Cultured phototrophic biofilms for phosphorus removal in wastewater treatment. Water Res 2008; 42(16): 4357-67. doi: 10.1016/j.watres.2008.07.029.

11. Al-Shatri AHA, Ali E, Al-Shorgani NKN, Kalil MS. Growth of Scenedesmus dimorphus in different algal media and $\mathrm{pH}$ profile due to secreted metabolites. African Journal of Biotechnology 2014; 13(16):1714-20. doi: 10.5897/ AJB2013.13455.

12. Chia MA, Musa RI. Effect of indigo dye effluent on the growth, biomass production and phenotypic plasticity of Scenedesmus quadricauda (Chlorococcales). An Acad Bras Cienc 2014; 86(1): 419-28.

13. Heidari S, Farhadian O, Soofiani NM. Biomass Production and ammonia and nitrite removal from fish farm effluent by Scenedesmus quadricauda culture. J Environ Stud 2011; 37(59):7.

14. Travieso L, Benitez F, Weiland P, Sánchez E, Dupeyrón
R, Dominguez AR. Experiments on immobilization of microalgae for nutrient removal in wastewater treatments. Bioresour Technol 1996; 55(3): 181-6. doi: 10.1016/09608524(95)00196-4.

15. Greenberg Arnold E, Clesceri Lenore S. Standard methods for the examination of water and wastewater. USA: American Public Health Association; 1992.

16. Ruiz-Martinez A, Serralta J, Seco A, Ferrer J. Effect of temperature on ammonium removal in Scenedesmus sp. Bioresour Technol 2015; 191: 346-9. doi: 10.1016/j. biortech.2015.05.070.

17. He P, Mao B, Lü F, Shao L, Lee D, Chang J. The combined effect of bacteria and Chlorella vulgaris on the treatment of municipal wastewaters. Bioresour Technol 2013; 146: 5628. doi: 10.1016/j.biortech.2013.07.111.

18. Roudsari FP, Mehrnia MR, Asadi A, Moayedi Z, Ranjbar R. Effect of microalgae/activated sludge ratio on cooperative treatment of anaerobic effluent of municipal wastewater. Appl Biochem Biotechnol 2014; 172(1): 131-40. doi: 10.1007/s12010-013-0480-z.

19. Sreesai S, Pakpain P. Nutrient recycling by Chlorella vulgaris from septage effluent of the Bangkok City, Thailand. ScienceAsia 2007;33(3):293-9.

20. Anand J, Arumugam M. Enhanced lipid accumulation and biomass yield of Scenedesmus quadricauda under nitrogen starved condition. Bioresour Technol 2015; 188: 190-4. doi: 10.1016/j.biortech.2014.12.097.

21. Shi J, Podola B, Melkonian M. Removal of nitrogen and phosphorus from wastewater using microalgae immobilized on twin layers: an experimental study. J Appl Phycol 2007; 19(5): 417-23. doi: 10.1007/s10811-006-9148-1.

22. Smith VH. The nitrogen and phosphorus dependence of algal biomass in lakes: an empirical and theoretical analysis. Limnol Oceanogr 1982; 27(6): 1101-11. doi: 10.4319/ lo.1982.27.6.1101.

23. Xin L, Hong-ying H, Ke G, Ying-xue S. Effects of different nitrogen and phosphorus concentrations on the growth, nutrient uptake, and lipid accumulation of a freshwater microalga Scenedesmus sp. Bioresour Technol 2010; 101(14): 5494-500. doi: 10.1016/j.biortech.2010.02.016.

24. Choi HJ, Lee SM. Effect of the N/P ratio on biomass productivity and nutrient removal from municipal wastewater. Bioprocess Biosyst Eng 2015;38(4): 761-6. doi: 10.1007/s00449-014-1317-z. 